\title{
Entrepreneurship Corner: Implementasi Program Kreativitas Mahasiswa Bidang Kewirausahaan (PKM-K)
}

\author{
Dadan Nugraha $^{1}$, Maulana ${ }^{2}$, Riana Irawati ${ }^{3}$, Dety Amelia Karlina ${ }^{4}$, Gilar Gandana
}

${ }^{1}$ Pendidikan Guru Sekolah Dasar, Universitas Pendikan Indonesia
2Pendidikan Guru Sekolah Dasar, Universitas Pendikan Indonesia
${ }^{3}$ Pendidikan Guru Sekolah Dasar, Universitas Pendikan Indonesia
${ }^{4}$ Pendidikan Guru Sekolah Dasar, Universitas Pendikan Indonesia
${ }^{5}$ Pendidikan Guru Sekolah Dasar, Universitas Pendikan Indonesia

Corresponding email: dadan@ upi.edu

\begin{abstract}
This service is aimed at fostering a climate, culture, spirit, and student entrepreneurial activities as well as encouraging the creation of independent graduates and becoming entrepreneurs through student entrepreneurship programs. The subject of this service is the PGSD UPI Sumedang Campus students. The outputs of this service include realization of an entrepreneurial fostering model that is effective in fostering and developing the entrepreneurial climate, culture, spirit, and student entrepreneurial activities, starting from the formulation of proposals, submitting proposals to passing funding ministry or university and the follow-up of student entrepreneurial activities.
\end{abstract}

Keywords: Entrepreneurship Corner, student entrepreneurship program.

\begin{abstract}
ABSTRAK
Pengabdian ini ditujukan menumbuhkembangkan iklim, budaya, jiwa, dan aktivitas kewirausahaan mahasiswa serta mendorong terciptanya lulusan yang mandiri dan menjadi wirausahawan melaui program-program kewirausahaan mahasiswa. Subjek pengabdian ini yaitu mahasiswa PGSD UPI Kampus Sumedang. Adapun luaran dari pengabdian ini antara lain terwujudnya model pembinaan kewirausahaan yang efektif dalam menumbuhkembangkan iklim, budaya, jiwa, dan aktivitas kewirausahaan mahasiswa baik dari mulai penyusunan proposal, pengajuan proposal, sampai lolos didanai baik oleh kementerian ataupun universitas serta tindak lanjut dari kegiatan kewirausahaan mahasiswa.
\end{abstract}

Kata kunci: Entrepreneurship Corner, program kewirausahaan mahasiswa. 


\section{PENDAHULUAN}

Salah satu Program Kreativitas Mahasiswa (PKM) yang diselenggarakan oleh Kementerian Pendidikan dan Kebudayaan (Kemendikbud) melalui Direktorat Pembelajaran dan Kemahasiswaan (Belmawa) yaitu Program Kreativitas Mahasiswa-Kewirausahaan (PKM-K). PKM-K didefinisikan sebagai program kreativitas mahasiswa dalam menciptakan aktivitas usaha. Tim mahasiswa harus melakukan analisis adanya kebutuhan dan peluang pasar, untuk selanjutnya membuat kreativitas (komoditas) usaha dalam rangka menyediakan kebutuhan pasar tersebut. Komoditas usaha PKM-K dapat berupa barang atau jasa yang merupakan karya kreativitas yang menunjukkan kepakaran tim mahasiswa. PKM$\mathrm{K}$ bertujuan untuk menumbuhkan pemahaman dan keterampilan mahasiswa dalam menghasilkan komoditas unik serta merintis kewirausahaan yang berorientasi pada profit. Dalam hal ini lebih mengutamakan keunikan dan kemanfaatan komoditas usaha (ada muatan intelektual) daripada profit. Pelaku utama adalah mahasiswa, sementara pihak lainnya hanya sebagai faktor pendukung. Selain itu tujuan PKM-K juga memotivasi dan membuka peluang bagi mahasiswa untuk menghasilkan karya kreatif, inovatif sebagai bekal berwirausaha sebelum atau setelah menyelesaikan studi. PKM-K diharapkan dapat menjadi cikal bakal kemunculan produk usaha di Indonesia sebagai karya mandiri bangsa.

Ruang lingkup PKM-K adalah menciptakan kreativitas usaha yang dijalankan oleh tim mahasiswa dengan kreativitas produk berupa barang atau jasa. Pada dasarnya, PKM-K lebih mengutamakan solusi tantangan intelektual yang mendasari lahirnya komoditas usaha baru dan unik. Komoditas usaha yang diciptakan harus merupakan jelmaan penguasaan ipteks oleh tim mahasiswa. Program PKM-K pada masa pandemi ini (dimungkinkan) dilaksanakan melalui konsep "blended", yaitu kombinasi tiga unsur penting, yaitu virtual-digital, online dan offline dengan tetap memperhatikan protokol kesehatan. Unsur-unsur tersebut dapat digunakan secara kombinasi maupun tunggal dalam pelaksanaan aktifitas 
usaha. Adapun luaran kegiatan PKM-K adalah aktivitas usaha dalam bentuk aktivitas wirausaha yang dijalankan tim mahasiswa.

Kriteria pengusul PKM-K ini adalah kelompok mahasiswa aktif program pendidikan S-1 yang terdaftar di PD-Dikti; berjumlah 3 (tiga) - 5 (lima) orang; tidak terikat bidang ilmu, namun bidang kegiatan disarankan sesuai dengan bidang ilmu ketua kelompok/tim dengan anggota dianjurkan berasal dari lintas bidang; mahasiswa pengusul dapat berasal dari berbagai program studi yang berbeda atau dari satu program studi yang sama dalam satu Perguruan Tinggi yang sama; dan keanggotaan setiap kelompok disarankan berasal dari minimal 2 (dua) angkatan yang berbeda agar terjadi pembinaan dan kesimbungan pengusulan program PKM tahun berikutnya.

Sejalan dengan program kementerian di atas, dalam rangka mewujudkan dan meningkatkan profil lulusan khususnya di Program Studi Pendidikan Guru Sekolah Dasar (PGSD) UPI Kampus Sumedang. Prodi PGSD juga menetapkan profil lulusannya yaitu sebagai guru SD, peneliti pendidikan bidang kesekolahdasaran, dan wirausahawan/wirausahawati bidang pendidikan kesekolahdasaran. Hal ini didukung pula dalam struktur kurikulumnya dengan adanya mata kuliah pendidikan kewirausahaan dan kewirausahaan sosial sebagai mata kuliah keahlian inti program studi. Mata Kuliah Kewirausahaan dutujukan untuk membentuk karakter wirausaha atau minimal mahasiswa menambah pengetahuannya mengenai seluk-beluk bisnis baik dari sisi soft skill maupun hard skill sehingga mahasiswa mampu memanfaatkan peluang- peluang yang ada di sekitarnya dalam menciptakan usaha sendiri setelah lulus maupun saat masih kuliah.

Namun pada kenyataannya masih ada kendala atau faktor penghambat yang dihadapi mahasiswa terkait implementasi program-program kewiraushaan khususnya PKM-K ini diantaranya 1) karakter dan rendahnya semangat berwirausaha berbasis keilmuan, sebagian mahasiswa beranggapan bahwa kompetensi tersebut bukan bagian dari keahlian yang harus dimilikinya, 2) kuantitas dan kualitas mahasiswa wirausaha, dibuktikan dengan jumlah proposal yang diajukan ataupun didanai masih relatif sedikit, 3) kurangnya unit bisnis mahasiswa sebagai dampak dari rendahnya semangat dan kuantitas serta kualitas 
mahasiswa wirausaha. Maka berdasarkan hal tersebut, salah satu alternatif solusinya yaitu Entrepreneurship Corner sebagai implementasi untuk menyukseskan Program Kreativitas Mahasiswa Bidang Kewirausahaan (PKM-K)

\section{TINJAUAN PUSTAKA}

Entrepreneur kali petama dikenalkan olej Richard Cantillon ekonom Prancis. Menurutnya entrepreneur adalah "agent who buys means of production at certain prices in order to combine them". Secara etimologis wirausaha berasal dari bahasa sansekerta terdiri dari tiga suku kata yaitu "wira, swa, dan sta". Wira berarti manusia unggul, teladan, tangguh, berbudi luhur, berjiwa besar, berani, pahlawan, pionir, pendekar/pejuang kemajuan, memiliki keagungan watak. Swa berarti sendiri dan sta berarti berdiri.

Istilah kewirausahaan, pada dasarnya berasal dari terjemahan entrepreneur yang dalam bahasa inggris dikenal dengan between taker atau go between. Konsep wirausaha secara lengkap dikemukakan oleh Josep Schumpeter, yaitu sebagai orang yang mendobrak sistem ekonomi yang ada dengan memperkenalkan barang dan jasa yang baru, dengan menciptakan bentuk organisasi baru atau mengolah bahan baku baru. Orang tersebut melakukan kegiatnnya melalui organisasi bisnis yang abru ataupun yang telah ada. Dalam definisi tersebut ditekankan bahwa wirausah adalah orang yang melihat adanya peluang kemudian menciptakan sebuah organsasi untuk memanfaatkan peluang tersebut. Sedangkan proses kewirausahaan adalah meliputi semua kegiatan fungsi dan tindakan untuk mengejar dan memanfaatkan peluang dengan menciptakan suatu organisasi.

Dari beberapa konsep yang ada, setidaknya ada 6 hakekat penting kewirausahaan yaiut 1). Kewirausaahan adalah suatu nilai yang diwujudkan dalam perilaku dan dijadikan dasar sumber daya, tenaga penggerak, tujuan, siasat, kiat, proses dan hasil bisnis (Achmad Sanusi, 1994); 2) kewirausahaan adalah suatu kemampaun untuk menciptakan suatu yang baru dan berbeda (Drucker, 1959); 3) Kewirausahan adalah suatu proses penerpaan kreativitas dan inovasi dalam memecahkan persoalan dan menemukan peluang untuk memperbaiki kehidupan (Zimmerer, 1996); 4) Kewirausahaan adalah suatu niali yang 
diperlukan untuk memuali suatu usaha dan perkembangan usaha (Soeharto Prawiro, 1997); 5) Kewirausahaan adalah suatu proses dalam mengerjakan sesautu yang baru dan berbeda serta memberi manfaat nilai lebih; 6) Kewirausaahn adalah usaha menciptakan nilai tambah dengan jalan mengkombinasikan sumber-sumber melalui cara baru dan berbeda untuk memenangkan persaingan. Nilai tambah tersebut dengan cara mengembangkan teknologi baru, pengetahuan baru, cara baru untu menghasilkan barang/jasa yang baru dan lebih efisien, memperbaiki produk dan jasa yang sudah ada, dan menemukan cara baru memberikan kepuasan konsumen. Berdasarkan keenam konsep diatas, secara ringkas kewirausahaan dapat didefinisikan sebagai sesuatu kemampuan kreatif dan inovatif (create new and different) yang dijadikan kiat, dasar, sumber daya, proses dan perjuangan untuk menciptakan nilai tambah barang dan jasa yang dilakukan dengan keberanian untuk menghadapi risiko.

\section{METODOLOGI PENELITIAN}

Subjek pengabdian ini yaitu mahasiswa PGSD UPI Kampus Sumedang. Kegiatan pengabdian ini menggunakan pendekatan partisipasi kolaboratif. Pendekatan ini didasarkan kepada hasil analisis terhadap masalah dan kebutuhan khalayak sasaran kemudian dirumuskan solusi alternatif. Kolaborasi antara khalayak sasaran dengan tim pengabdian dilaksanakan mulai dari identifikasi masalah, perumusan solusi alternatif dan implementasi solusi di lapangan. Selain itu, kolaborasi juga dilaksanakan pada tahap monitoring dan evaluasi pencapaian target luaran atau produk. Secara garis besar metode pelaksanaannya dipaparkan sebagai berikut. a) Tahap persiapan, yakni penyiapan tim program serta sosialisasi program. b) Tahap pelaksanaan, diawali dengan pendaftaran tim kewirausahaan; penyusunan proposal kewirausahaan oleh tim kewirausahaan mahasiswa; pendampingan penyusunan proposal kewirausahaan; seleksi proposal kewirausahaan baik seleksi administrasi ataupun seleksi presentasi; perbaikan proposal kewirausahaan setelah proses seleksi. c) Monitoring dan evaluasi. 


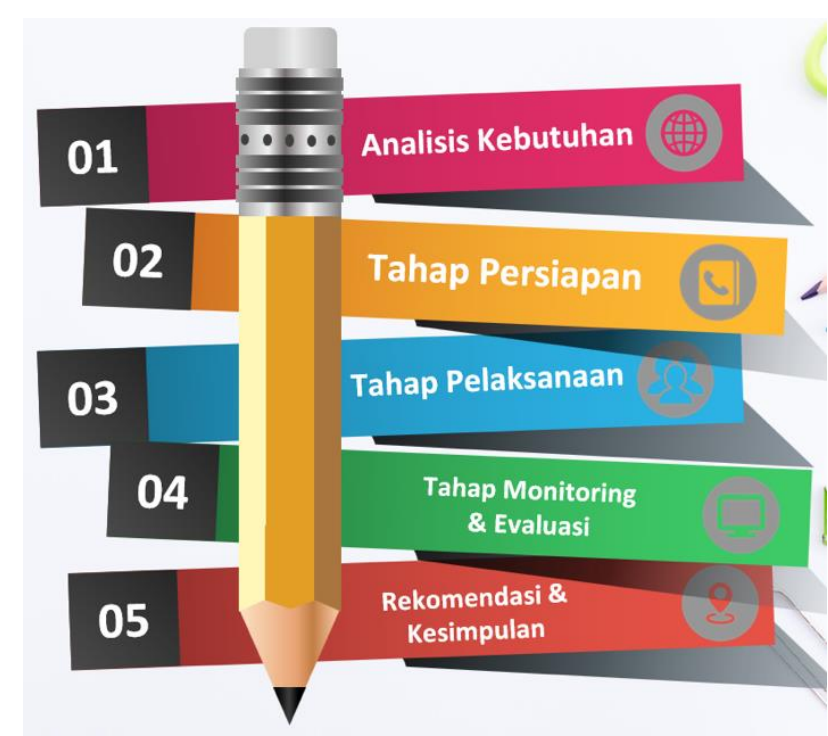

Gambar 1. Bagan Alir Kegiatan Pengabdian

\section{HASIL DAN PEMBAHASAN}

Deskripsi hasil pengabdian Entrepreneurship Corner : Implementasi Program Kreativitas Mahasiswa Bidang Kewirausahaan (PKM-K) dijelaskan sebagai berikut.

1. Tahap Persiapan

Tahap persiapan diawali dengan penyiapan tim program yang terdiri dari tim pengabdian, dosen, mahasiswa dan alumni yang mendapatkan dana PKM$\mathrm{K}$, selanjutnya kegiatan sosialisasi progam ditujukan kepada pimpinan, dosen pendamping dan seluruh mahasiswa PGSD UPI Kampus Sumedang. Sosialisasi ini dalam rangka menyampaikan program Entrepreneurship Corner sebagai implementasi Program Kreativitas Mahasiswa khususnya bidang Kewirausahaan (PKM-K), dengan harapan semua komponen baik pimpinan, dosen ataupun mahasiswa secara proaktif ikut menyukseskan program tersebut. 


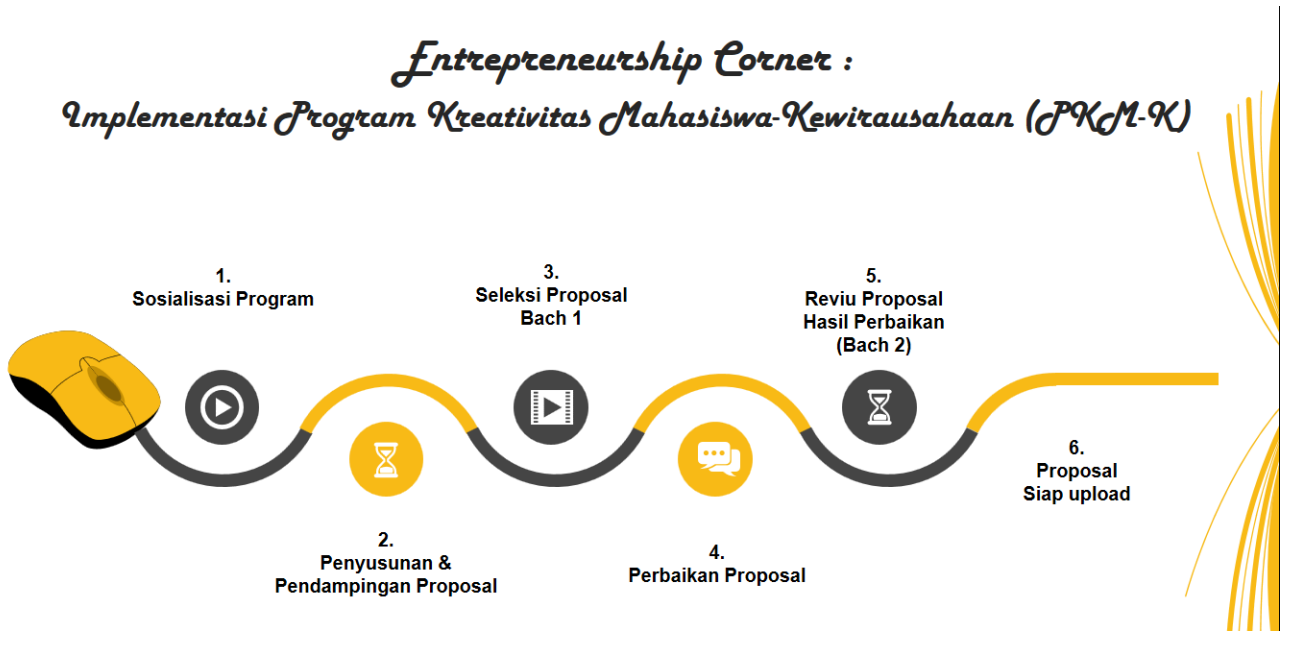

Gambar 2. Program Entrepreneurship Corner

2. Tahap Pelaksanaan

Setelah sosialisasi program dilaksanakan, tahap selanjutnya adalah tahap pelaksanaan terdiri dari a) pendaftaran tim kewirausahaan mahasiswa; b) penyusunan dan pendampingan proposal kewirausahaan; c) seleksi proposal kewirausahaan baik seleksi administrasi ataupun seleksi presentasi; d) perbaikan proposal kewirausahaan setelah proses seleksi; dan d) reviu proposal hasil perbaikan sehingga proposal siap di upload.

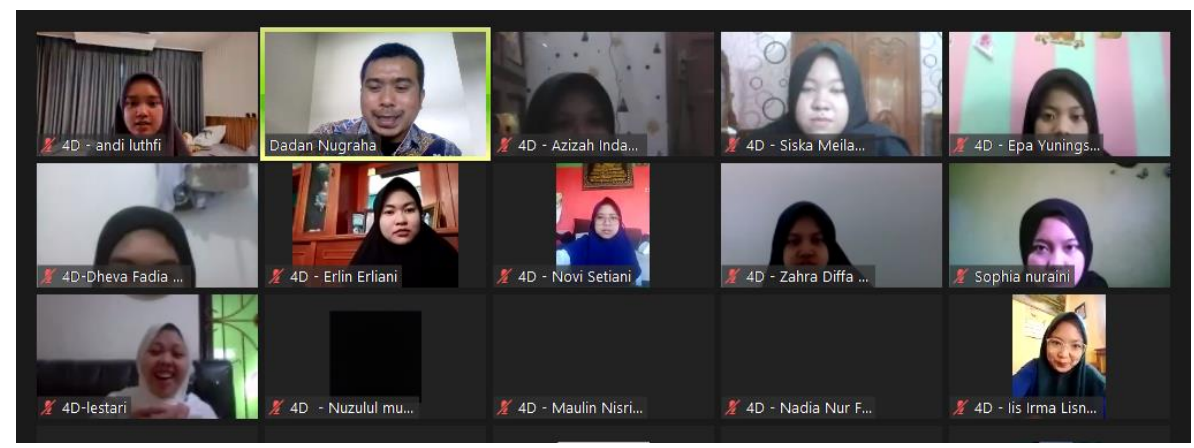

Gambar 3. Dokumentasi Kegiatan

Ada 21 tim yang mendaftarkan diri untuk ikut seleksi program kreativitas mahasiswa-kewirausahaan (PKM-K) ini. Sekitar 105 mahasiswa yang terlibat dan 10 dosen pendamping. Kreativitas (komoditas) usaha yang dirancang mahasiswa berfokus kepada produk barang seperti, makanan, fashion, e-book, dll. Selama penyusunan proposal ini tim mahasiswa didampingi oleh dosen pendamping masing-masing yang sebelumnya telah dipilih oleh tim mahasiswa, dosen pendamping ini sejatinya memberikan arahan dan 
bimbingan terkait proposal yang dirancang mahasiswa baik syarat administrasi ataupun ide kreativitas proposal yang dirancang. Setelah selesai penyusunan proposal, selanjutnya seleksi proposal baik administrasi maupun presentasi oleh tim, hasil dari seleksi ini adalah rekomendasi perbaikan proposal sehingga akhirnya proposal siap untuk di upload.

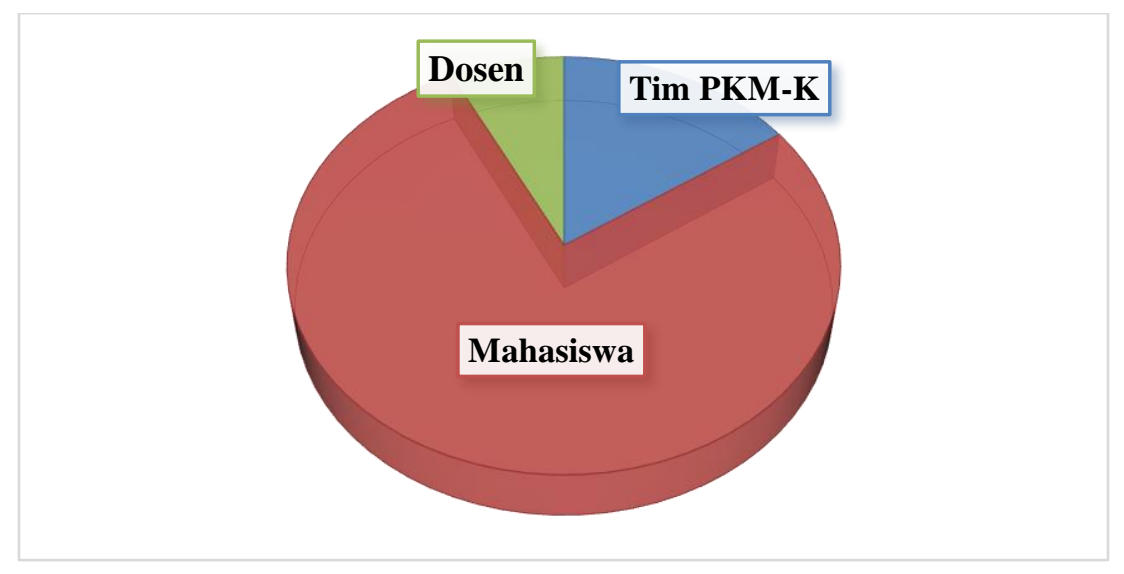

Gambar 4. Keterlibatan Tim, Mahasiswa dan Dosen Pendamping

Salah satu indikator keberhasilan dari program pengabdian ini yaitu 1) Semangat berwirausaha berbasis keilmuan, karena kompetensi tersebut juga bagian dari keahlian yang harus dimiliki mahasiswa, 2) Kuantitas dan kualitas mahasiswa berwirausaha, dibuktikan dengan jumlah proposal yang diajukan dan jumlah mahasiswa yang terlibat, 3) bertambahnya unit bisnis mahasiswa sebagai dampak dari semangat berwirausha dan kuantitas serta kualitas proposal yang diajukan oleh mahasiswa untuk mendapatkan pendanaan dari Kementerian Pendidikan dan Kebudayaan (Kemendikbud) melalui Direktorat Pembelajaran dan Kemahasiswaan (Belmawa).

3. Tahap monitoring dan evaluasi

Secara umum, kegiatan pengadian ini berjalan dengan lancar, efektif dan efisien. Diharapkan pada tahun-tahun berikutnya semakin banyak lagi mahasiswa dan dosen yang terlibat dalam program kreativitas mahasiswakewiraushaan (PKM-K), sehingga kuantitas proposal yang didanai oleh Kemendikbud bertambah serta kualitas proposal yang dirancang mahasiswa semakin baik. 


\section{KESIMPULAN}

Entrepreneurship Corner sebagai kegiatan pengabdian dalam rangka mengimplementasikan program kreativitas mahasiswa-kewirausahaan (PKM-K) kepada mahasiswa PGSD UPI Kampus Sumedang berjalan dengan efektif dan efisien. Indikator keberhasilan dari pengabdian ini yaitu 1) Meningkatnya semangat berwirausaha mahasiswa berbasis keilmuan, 2) Kuantitas dan kualitas mahasiswa berwirausaha, 3) Bertambahnya unit bisnis mahasiswa sebagai dampak dari semangat berwirausha dan kuantitas serta kualitas proposal yang diajukan untuk mendapatkan pendanaan dari Kementerian Pendidikan dan Kebudayaan (Kemendikbud)

\section{ACKNOWLEDGMENT}

Atas izin Allah SWT, Alhamdulillah kegiatan pengabdian ini berjalan dengan lancar. Kami segenap tim pengabdian mengucapkan terima kasih kepada seluruh pihak yang telah membantu. Rektor dan LPPM Universitas Pendidikan Indonesia (UPI), Direktur UPI Kampus Sumedang, Ketua Program Studi PGSD UPI Kampus Sumedang dan seluruh mahasiwa sebagai mitra dalam pengabdian ini.

\section{DAFTAR PUSTAKA}

Direktorat Kemahasiswaan - Dirjen Belmawa Kemdikbud (2020). Buku 1 Panduan Umum Program Kreativitas Mahasiswa. Jakarta : Kemdikbud.

Direktorat Kemahasiswaan - Dirjen Belmawa Kemdikbud (2020). Buku 3 PKM Kewirausahaan. Jakarta : Kemdikbud.

Direktorat Pembelajaran dan Kemahasiswaan - Dirjen Dikti Kemdikbud (2020). Adendum Pedoman PKM 5 Bidang Tahun 2020. Jakarta : Kemdikbud.

Direktorat Kemahasiswaan UPI (2019). Program Mahasiswa Wirausaha (PMW). Bandung : UPI.

Direktorat Kemahasiswaan UPI (2020). Panduan Teknis Program Mahasiswa Wirausaha. Bandung : UPI.

Hardini, T. Indri. (2021). Penyamaan persepsi reviewer internal FPBS UPI Program Kreativitas Mahasiswa. Bandung : FPBS UPI. 
Kemdikbud - Direktorat Belmawa. (2021). Buku Pedoman 1 Program Kreativitas Mahasiswa. Jakarta : Kemdikbud.

Kemdikbud - Direktorat Belmawa. (2021). Buku Pedoman 3 Program Kreativitas Mahasiswa Kewirausahaan (PKM-K). Jakarta : Kemdikbud.

LPPM UPI. (2021). Panduan Pelaksanaan Penelitian dan Pengabdian Kepada Masyarakat Universitas Pendidikan Indonesia Tahun 2021. Bandung : UPI.

Modul Pembelajaran Kewirausahaan. (2013). Direktorat Jenderal Pembelajaran dan Kemahasiswaan Ditjen Pendidikan Tinggi Kementerian Pendidikan dan Kebudayaan.

Tim PKM UPI, (2021). Pedoman Penyiapan Proposal PKM UPI Tahun 2021. Bandung : Tim PKM UPI. 